\title{
MicroRNA-200b acts as a tumor suppressor in osteosarcoma via targeting ZEBI
}

This article was published in the following Dove Press journal:

OncoTargets and Therapy

24 May 2016

Number of times this article has been viewed

\section{Yusheng $\mathrm{Li}^{\prime}$ \\ Chao Zeng' \\ Min $\mathrm{Tu}^{2}$ \\ Wei Jiang ${ }^{3}$ \\ Zixun Dai ${ }^{4}$ \\ Yuling $\mathrm{Hu}^{5}$ \\ Zhenhan Deng' \\ Wenfeng Xiao'}

'Department of Orthopedics, Xiangya Hospital Central South University, Changsha, Hunan, ${ }^{2}$ Department of Orthopedics, Second People's Hospital of Jingmen, Jingmen, Hubei, ${ }^{3}$ Department of Bone and Joint, Shenzhen People's Hospital, Second Clinical Medical College of Jinan University, Shenzhen, Guangdong, ${ }^{4}$ Department of Orthopedics, The Affiliated Cancer Hospital of Xiangya School of Medicine, ${ }^{5}$ Department of Clinical Medicine, Xiangya School of Medicine, Central South University, Changsha, Hunan, People's Republic of China
Correspondence: Wenfeng Xiao Department of Orthopedics, Xiangya Hospital Central South University, 87 Xiangya Road, Changsha, Hunan 4I0008, People's Republic of China

Tel/fax +86 73I 89753006

Email boneswenfeng@163.com

\begin{abstract}
Osteosarcoma is the most common type of cancer that develops in bone, mainly arising from the metaphysis of the long bones. MicroRNA (miR)-200b has been found to generally act as a tumor suppressor in multiple types of human cancers. However, the detailed role of miR-200b in osteosarcoma still remains to be fully understood. This study aimed to investigate the exact role of miR-200b in the progression of osteosarcoma and the underlying mechanism. Real-time reverse transcription-polymerase chain reaction data showed that miR-200b was significantly downregulated in osteosarcoma tissues compared to their matched adjacent nontumor tissues. Low miR-200b level was associated with the advanced clinical stage and positive distant metastasis. Besides, it was also downregulated in osteosarcoma cell lines (U2OS, Saos2, HOS, and MG63) compared to normal osteoblast cell line NHOst. In vitro study showed that restoration of miR-200b led to a significant decrease in proliferation, migration, and invasion of osteosarcoma cells. Moreover, ZEB1 was identified as a target gene of miR-200b, and its expression levels were negatively mediated by miR-200b in osteosarcoma cells. In addition, ZEB1 was significantly upregulated in osteosarcoma cells compared to the normal osteoblast cell line NHOst, and inhibition of ZEB1 expression also suppressed the proliferation, migration, and invasion in osteosarcoma cells. Finally, we showed that ZEB1 was frequently upregulated in osteosarcoma tissues compared to their matched adjacent normal tissues, and its expression was reversely correlated to the miR-200b levels in osteosarcoma tissues. Based on these findings, our study suggests that miR-200b inhibits the proliferation, migration, and invasion of osteosarcoma cells, probably via the inhibition of ZEB1 expression. Therefore, miR-200b/ZEB1 may become a potential target for the treatment of osteosarcoma.
\end{abstract}

Keywords: osteosarcoma, microRNA-200b, proliferation, migration, invasion, metastasis

\section{Introduction}

Osteosarcoma is the most common type of cancer that develops in bone, mainly arising from the metaphysis of the long bones. ${ }^{1}$ Despite the development of cancer treatment over the past few decades, the prognosis of advanced osteosarcoma still remains poor, mainly due to its resistance to radiotherapy, chemotherapy, and adjuvant therapies. ${ }^{2}$ Understanding the molecular mechanism of osteosarcoma is urgently needed for the development of effective therapeutic strategy. ${ }^{3}$

MicroRNAs (miRs) are a class of noncoding RNAs 18-25 nucleotides in length and generally lead to messenger RNA (mRNA) degradation or inhibition of translation via directly binding to $3^{\prime}$-untranslated regions (3'-UTRs) of mRNA of their target genes. ${ }^{4}$ Through negatively mediating their target genes, miRs are involved in a variety of biological processes, such as cell survival, proliferation, apoptosis, differentiation, migration, and tumorigenesis. ${ }^{5}$ Moreover, various miRs have been found to be associated with the development and progression of osteosarcoma and thus may become potential therapeutic targets or candidates. ${ }^{3}$ 
Among those miRs associated with human cancers, miR$200 \mathrm{~b}$ has been found to be frequently downregulated in human cancers and generally act as a tumor suppressor. ${ }^{6,7}$ For instance, Yao et al found that miR-200b was significantly downregulated in breast cancer, and the low expression of miR-200b was correlated with late tumor-node-metastasis stage and poor prognosis. ${ }^{6}$ Besides, overexpression of miR-200b inhibited the proliferation while inducing the apoptosis of breast cancer cells probably via targeting Sp $1 .{ }^{6}$ Williams et al found that miR-200b inhibits epithelial-to-mesenchymal transition (EMT), growth, and metastasis of prostate cancer. ${ }^{7}$ Besides, it was also suggested to play a suppressive role in some other cancers, such as prostate cancer, cholangiocarcinoma, gastric cancer, bladder cancer, hepatocellular carcinoma, and tongue squamous cell carcinoma. ${ }^{8-13}$ Recently, Li et al reported that diallyl trisulfide treatment inhibited the proliferation, invasion, and angiogenesis of osteosarcoma cells, accompanied with miR-200b upregulation. ${ }^{14}$ They further found that enforced expression of miR-200b resulted in the downregulation of Notch1, which could lead to the inhibition of osteosarcoma cell proliferation, invasion, and angiogenesis. ${ }^{14}$ Accordingly, miR-200b also acts as a tumor suppressor in osteosarcoma. However, the detailed role of miR-200b in the malignant progression of osteosarcoma and the underlying mechanism still remains to be fully understood.

In this study, we examined the expression pattern of miR$200 \mathrm{~b}$ in osteosarcoma specimens. Moreover, we investigated the role of miR-200b in the regulation of the malignant phenotypes of osteosarcoma cells and the underlying mechanisms.

\section{Materials and methods}

\section{Clinical specimens}

The study was approved by the Ethics Committee of Central South University, Changsha, People's Republic of China. A total of 32 cases of osteosarcoma specimens and their matched adjacent nontumor tissues were obtained from Xiangya Hospital of Central South University between March 2010 and March 2013. All patients with osteosarcoma included 14 females and 18 males who ranged in age from 13 to 43 years, with a mean of 27.7 years. The clinicopathological information of patients involved in our study is summarized in Table 1. Before surgical resection, no patient received radiotherapy or chemotherapy. Tissue samples were stored at $-80^{\circ} \mathrm{C}$ before use. Written consents have been obtained from all participants.

\section{Cell culture}

Human osteosarcoma cell lines U2OS, Saos2, HOS, and MG63 and normal osteoblast cell line NHOst were purchased from the Cell Bank of Central South University. All the
Table I Correlation between miR-200b expression and clinicopathologic features of patients with osteosarcoma

\begin{tabular}{|c|c|c|c|c|}
\hline \multirow{2}{*}{$\begin{array}{l}\text { Clinicopathologic } \\
\text { features }\end{array}$} & \multirow{2}{*}{$\begin{array}{l}\text { Cases } \\
\text { (n) }\end{array}$} & \multicolumn{2}{|c|}{ 200b expression } & \multirow[t]{2}{*}{$P$-value } \\
\hline & & $\begin{array}{l}\text { High, } \\
\text { n (\%) }\end{array}$ & $\begin{array}{l}\text { Low, } \\
\text { n (\%) }\end{array}$ & \\
\hline \multicolumn{5}{|l|}{ Sex } \\
\hline Male & 15 & $6(40.0)$ & $9(60.0)$ & NS \\
\hline Female & 17 & $7(4 \mid .2)$ & $10(58.8)$ & \\
\hline \multicolumn{5}{|l|}{ Age (years) } \\
\hline$\leq 28$ & 19 & $8(42.1)$ & II (57.9) & NS \\
\hline$>28$ & 13 & $5(38.5)$ & $8(61.5)$ & \\
\hline \multicolumn{5}{|l|}{ Tumor size (diameter) } \\
\hline$\leq 5 \mathrm{~cm}$ & 14 & $6(42.8)$ & $8(59.6)$ & NS \\
\hline$>5 \mathrm{~cm}$ & 18 & $7(38.9)$ & II (6I.I) & \\
\hline \multicolumn{5}{|l|}{ WHO grade } \\
\hline I and II & 12 & $9(75.0)$ & $3(25.0)$ & 0.0001 \\
\hline III and IV & 20 & $4(20.0)$ & $16(80.0)$ & \\
\hline \multicolumn{5}{|l|}{ Distant metastasis } \\
\hline Positive & 13 & $2(15.4)$ & II (84.6) & 0.0001 \\
\hline Negative & 19 & II (57.9) & $8(42.1)$ & \\
\hline
\end{tabular}

Abbreviations: miR, microRNA; NS, not significant; WHO, World Health Organization.

cells were cultured in Dulbecco's Modified Eagle's Medium (DMEM; Thermo Fisher Scientific, Waltham, MA, USA) added with $10 \%$ fetal bovine serum (FBS; Thermo Fisher Scientific), $100 \mathrm{IU} / \mathrm{mL}$ penicillin, and $100 \mathrm{IU} / \mathrm{mL}$ streptomycin. Cells were cultured at $37^{\circ} \mathrm{C}$ in a humidified atmosphere with $5 \% \mathrm{CO}_{2}$.

\section{Transfection}

To overexpress miR-200b or knock down miR-200b, U2OS and MG63 cells were transfected with miR-200 mimics or miR-200b inhibitors (RiboBio Co., Ltd., Guangzhou, People's Republic of China) for 48 hours by Lipofectamine 3000 (Thermo Fisher Scientific) in accordance with the manufacturer's instructions. The cells transfected with scramble sequence were used as a negative control.

In order to knock down the expression of ZEB1, we transfected ZEB1 small interfering RNA (siRNA) with the final concentration at $200 \mathrm{nmol}$ (catalog number: Q0000069351-B, RiboBio Co., Ltd.) into U2OS and MG63 cells by Lipofectamine 3000 (Thermo Fisher Scientific) in accordance with the manufacturer's instructions. After 48-hour transfection, the cells were used for further analysis.

\section{Real-time reverse transcription PCR assay}

Total RNA was extracted using TRIzol reagent (Thermo Fisher Scientific) according to the manufacturer's instructions. MicroRNA reverse transcription kit (Thermo Fisher Scientific) was used to convert $10 \mathrm{ng}$ of total RNA into complementary 
DNA, according to the manufacturer's instructions. The miRNA expression was determined on ABI 7500 thermocycler (Thermo Fisher Scientific) using PrimeScript ${ }^{\circledR}$ miRNA RT-PCR Kit (Takara, Dalian, People's Republic of China), in accordance with the manufacturer's instructions. The polymerase chain reaction (PCR) conditions were $95^{\circ} \mathrm{C}$ for 10 minutes followed by 40 cycles of denaturation at $95^{\circ} \mathrm{C}$ for 15 seconds and annealing/elongation step at $60^{\circ} \mathrm{C}$ for $1 \mathrm{~min}$ ute. The relative miR-200b expression was normalized to U6. The relative expression was analyzed by the $2^{-\Delta \Delta \mathrm{Ct}}$ method. ${ }^{15}$

\section{Western blot}

Cells were solubilized in cold radioimmunoprecipitation assay (RIPA) lysis buffer (Thermo Fisher Scientific) to extract protein, which was separated with $10 \%$ sodium dodecyl sulfate polyacrylamide gel electrophoresis (Pierce Biotechnology, Rockford, IL, USA), and transferred onto a polyvinylidene difluoride membrane (Pierce Biotechnology). The polyvinylidene difluoride membrane was then incubated with phosphate-buffered saline containing $5 \%$ milk overnight at $4{ }^{\circ} \mathrm{C}$ and then incubated with rabbit anti-ZEB1 polyclonal antibody (1:50, Abcam, Cambridge, MA, USA) and rabbit anti-GAPDH polyclonal antibodies (1:100, Abcam) at room temperature for 3 hours, respectively, and then with HRPlinked goat anti-rabbit secondary antibody (1:5,000, Abcam) at room temperature for 40 minutes. Super Signal West Pico Chemiluminescent Substrate Kit (Pierce Biotechnology) was then used to detect signals, according to the manufacturer's instructions. The relative protein expression was analyzed by Image-Pro Plus software 6.0 (Roper Industries, Rockville, MD, USA), represented as the density ratio versus GAPDH.

\section{Bioinformatics prediction}

We screened the target genes of miR-200b using algorithms such as PicTar, ${ }^{16}$ TargetScan, ${ }^{17}$ and miRanda. ${ }^{18}$

\section{Luciferase reporter gene assay}

The full-length 3'-UTR of ZEB1 was amplified from human genomic DNA and then cloned into the downstream of the firefly luciferase coding region of pMIR-GLOTM Luciferase vector (Promega Corporation, Fitchburg, WI, USA), named as pMIR-ZEB1. Mutations of miR-200b binding sites were introduced by site-directed mutagenesis, which was then cloned into the downstream of the firefly luciferase coding region of pMIR-GLOTM Luciferase vector, named as pMIR-Mut ZEB1. The site-directed mutagenesis was performed in RiboBio Co., Ltd. After that, U2OS and MG63 cells were seeded into 24-well plates and cotransfected with $200 \mathrm{ng}$ of pMIR-ZEB1 or pMIR-ZEB1-Mut vector and
$100 \mathrm{ng}$ of miR-200b mimic or scramble miR mimic, and the pRL-TK plasmid (Promega Corporation) as internal normalization. Cells were harvested after 36 hours and lysed using the lysis buffer (Promega Corporation). Luciferase reporter gene assay was conducted by the Dual-Luciferase Reporter Assay System (Promega Corporation), in accordance with the manufacturer's instructions.

\section{Cell proliferation assay}

U2OS and MG63 cells were seeded in a 96-well plate at a density of 10,000 cells per well. After culturing for different times, U2OS and MG63 cells were incubated with MTT (0.5 mg/mL; Thermo Fisher Scientific) for 4 hours at $37^{\circ} \mathrm{C}$, and then DMSO $(150 \mathrm{mM})$ was added to dissolve the formazan crystals. The absorbance was read at $570 \mathrm{~nm}$ using a multiwell scanning spectrophotometer reader (Runqee (Shanghai) Instruments Technology Co., Ltd).

\section{Cell migration assay}

U2OS and MG63 cells were cultured to full confluence. Wounds of $\sim 1 \mathrm{~mm}$ width were created. U2OS and MG63 cells were washed and then incubated in DMEM added with $10 \% \mathrm{FBS}$ for 36 hours at $37^{\circ} \mathrm{C}$. After that, U2OS and MG63 cells were fixed with $90 \%$ alcohol and observed under an inverted microscope (Olympus Corporation, Tokyo, Japan). The relative migratory rate was calculated by measuring the width of scratch of each group and then normalizing to the width of scratch of control group at 0 hour.

\section{Cell invasion assay}

U2OS and MG63 cell suspension containing $5 \times 10^{5}$ cells $/ \mathrm{mL}$ was prepared in serum-free DMEM, and $300 \mu \mathrm{L}$ of cell suspension was added into the upper chamber of the transwell chambers (BD Pharmingen, San Diego, CA, USA), which had been precoated with Matrigel. Then, $500 \mu \mathrm{L}$ of DMEM added with $10 \%$ FBS was added into the lower chamber. After incubation for 24 hours at $37^{\circ} \mathrm{C}$, cells that did not invade through the pores were carefully wiped out by a cotton-tipped swab. The filters were fixed in $90 \%$ alcohol and stained by $0.1 \%$ crystal violet. Cells through the pores were observed and counted under an inverted microscope (Olympus Corporation).

\section{Statistical analysis}

Data were expressed as mean \pm standard deviation from three separate experiments. Comparison of PCR data was analyzed by the unpaired $t$-test. Qualitative data were analyzed by the chi-square test. SPSS17.0 (SPSS Inc., Chicago, IL, USA) was 
used to conduct statistical analysis. $P<0.05$ was considered statistically significant.

\section{Results}

\section{MiR-200b is significantly downregulated in osteosarcoma and is associated with malignant progression}

In this study, real-time reverse transcription PCR was first performed to determine the expression levels of miR-200b in osteosarcoma tissues as well as their matched adjacent nontumor tissues. As shown in Figure 1A, the miR-200b levels were significantly decreased in osteosarcoma specimens when compared to their matched adjacent nontumor tissues. To further confirm that miR-200b is downregulated in osteosarcoma, we further examined its expression in four common human osteosarcoma cell lines (U2OS, Saos2, HOS, and MG63) and the normal osteoblast cell line NHOst. As demonstrated in Figure 1B, the expression level of miR-200b was also decreased in osteosarcoma cell lines compared to NHOst cells.

The patients with osteosarcoma were further divided into two groups according to the mean value of the miR$200 \mathrm{~b}$ expression as the cutoff point. As shown in Table 1, 19 cases of patients with osteosarcoma (59.38\%) were in low-miR-200b-level group, and 13 cases of patients with osteosarcoma (40.63\%) were in high-miR-200b-level group. We further analyzed the association of miR-200b levels with clinicopathological features of osteosarcoma. We found no statistically significant association of miR-200b level with the age, sex, and tumor size (both $P>0.05$; Table 1). However, the high-grade osteosarcoma (grades III and IV) showed lower miR-200b levels compared to the low-grade osteosarcoma tissues (grades I and II) $(P<0.001$; Table 1$)$. Besides, low miR-200b level was also associated with positive distant metastasis $(P<0.001$; Table 1). Accordingly, we demonstrated that the lower miR-200b level was associated with the higher malignance of osteosarcoma and suggested that the downregulation of miR-200b might be involved in the malignant progression of osteosarcoma.

\section{Enforced expression of miR-200b inhibits the proliferation, migration, and invasion of osteosarcoma cells}

As U2OS and MG63 cells showed the significant decrease in miR-200b levels, these two cell lines were transfected with miR-200b mimic to restore the expression level of miR-200b. As shown in Figure 2A, miR-200b was significantly upregulated in U2OS and MG63 cells transfected with miR-200b mimic, when compared to the control group, respectively. MTT assay was then conducted to examine the cell proliferation. As demonstrated in Figure 2B and C, enforced expression of miR-200b led to a significant decrease in proliferation of U2OS and MG63 cells, suggesting that miR-200b plays a suppressive role in osteosarcoma growth. We then investigated the role of miR-200b in the regulation of the migration and invasion of osteosarcoma cells. As shown in Figure 3A, enforced expression of miR-200b inhibited the migration of U2OS and MG63 cells, when compared to the control group. Similarly, enforced expression of miR-200b also led to a significant reduction in U2OS and MG63 cell invasion (Figure 3B). It is possible that the inhibition of cell migration and invasion of osteosarcoma cells caused by overexpression of miR-200b and downregulation of ZEB1 may be partially due to the inhibition of cell proliferation. Therefore, we suggest that miR-200b may also act as a tumor suppressor in osteosarcoma metastasis.

\section{MiR-200b directly targets ZEBI in osteosarcoma cells}

TargetScan, PicTar, and miRanda were further used to predicate the putative target genes of miR-200b. As demonstrated in Figure 4A, ZEB1 is a putative target gene of miR-200b. Luciferase reporter assay was further conducted
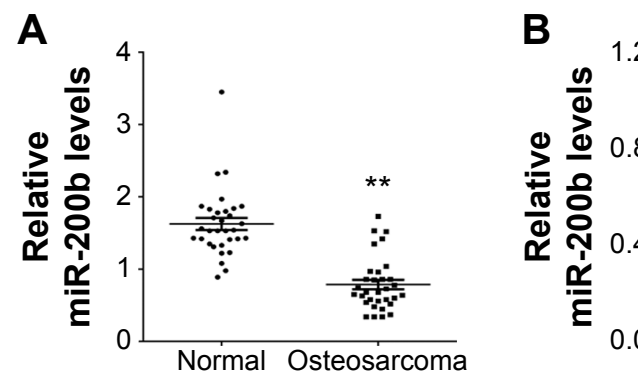

Figure I miR-200b expression in osteosarcoma tissues and cells.

Notes: (A) Real-time RT-PCR was conducted to determine the relative miR-200b level in 32 cases of osteosarcoma tissues and their matched adjacent normal tissues. **P $<0.0$ I versus normal. (B) Real-time RT-PCR was conducted to determine the relative miR-200b level in osteosarcoma U2OS, Saos2, HOS, and MG63 and normal osteoblast cell line NHOst. $* * P<0.01$ versus $\mathrm{NHOst}$. The error bars indicate standard deviation.

Abbreviations: miR, microRNA; RT-PCR, reverse transcription-polymerase chain reaction. 
A

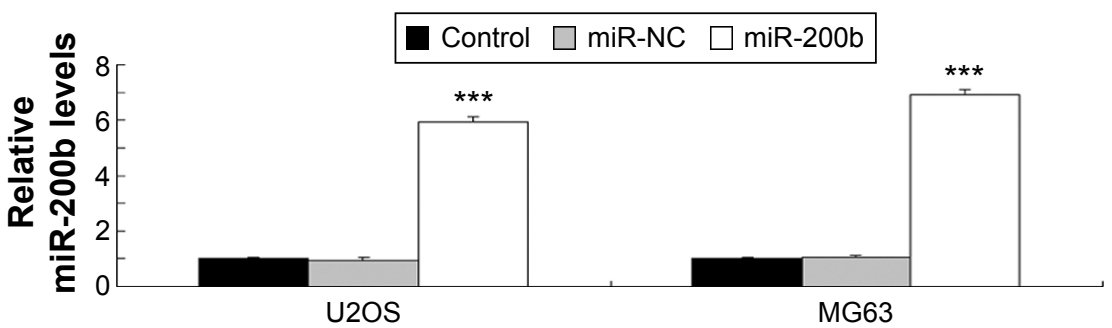

B $\widehat{\varepsilon}$
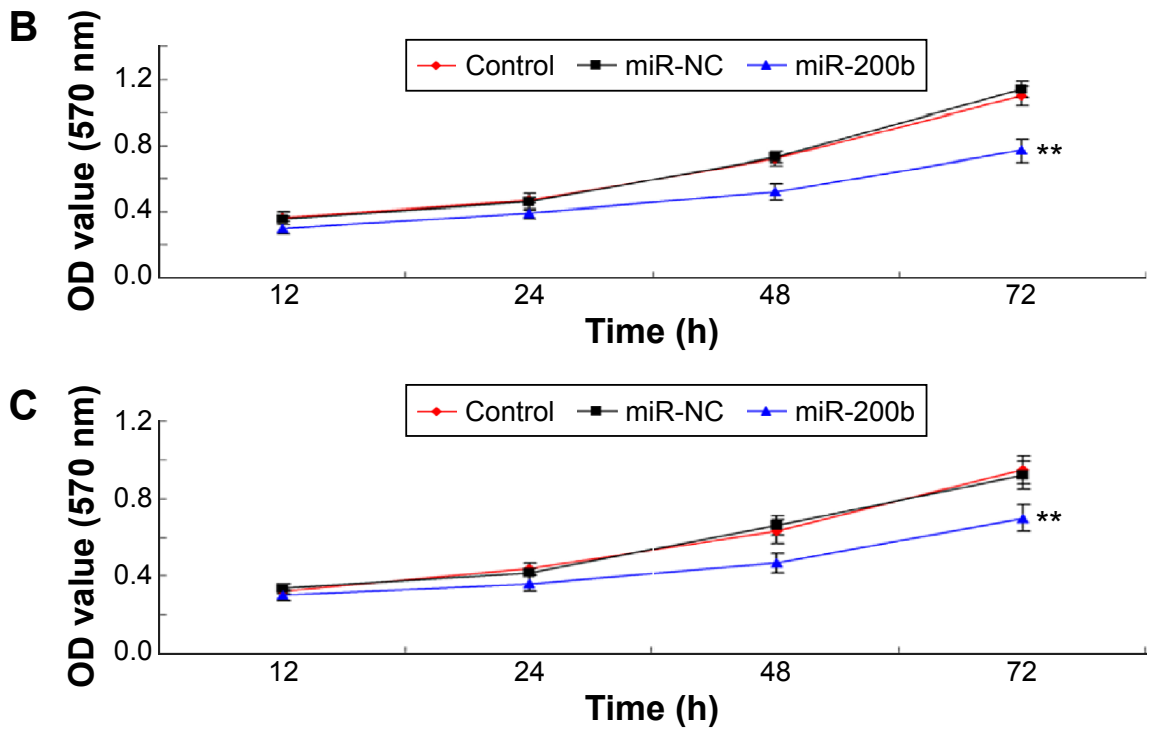

Figure 2 miR-200b inhibits proliferation of U2OS and MG63 cells.

Notes: (A) Real-time RT-PCR was conducted to determine the relative miR-200b level in osteosarcoma U2OS and MG63 cells transfected with miR-200b mimic or scramble miR (miR-NC). MTT assay was performed to determine cell proliferation in U2OS (B) and MG63 (C) cells. Nontransfected U2OS and MG63 cells were used as control. $* * P<0.01$, $* * * P<0.001$ versus miR-NC. The error bars indicate standard deviation.

Abbreviations: miR, microRNA; RT-PCR, reverse transcription-polymerase chain reaction; NC, negative control; OD, optical density; h, hours.

in $293 \mathrm{~T}$ cells to confirm this predication (Figure 4B). As shown in Figure 4C and D, cotransfection with pMIRZEB1 plasmid and miR-200b mimic markedly decreased the luciferase activity, while cotransfection with pMIRMut ZEB1 plasmid and miR-200b mimic showed no effect on the luciferase activity. Accordingly, these data indicate that miR-200b directly binds to the $3^{\prime}$-UTR of ZEB1 mRNA.

After that, we further determined the effects of miR-200b levels on the expression of ZEB1 in osteosarcoma cells. First, U2OS and MG63 cells were transfected with miR-200b mimic or inhibitor to upregulate or downregulate its expression, respectively. As demonstrated in Figure 5A, transfection with miR-200b mimic led to a significant increase in miR$200 \mathrm{~b}$ level, while transfection with miR-200b inhibitor led to a significant decrease in miR-200b level, compared to the control group. We then found that upregulation of miR-200b inhibited the protein expression of ZEB1, while knockdown of miR-200b enhanced the protein level of ZEB1 in osteosarcoma U2OS and MG63 cells (Figure 5B). Accordingly, miR-200b negatively regulates the ZEB1 protein expression, partly at least, via directly binding to the 3'-UTR of ZEB1 mRNA in osteosarcoma cells.

\section{Knockdown of ZEBI also inhibits the proliferation, migration, and invasion of osteosarcoma cells}

As miR-200b negatively mediated the protein level of ZEB1 in osteosarcoma cells, we speculated that ZEB1 might be involved in miR-200b-mediated inhibition of osteosarcoma growth and metastasis. We found that ZEB1 was notably upregulated in osteosarcoma cell lines compared to normal osteoblast cell line NHOst (Figure 6A). After that, U2OS and MG63 cells were transfected with ZEB1 siRNA to downregulate its expression. As demonstrated in Figure 6B, the protein level of ZEB1 was significantly reduced after transfection with ZEB1 siRNA in U2OS and MG63 cells. We further examined the cell proliferation, migration, and invasion. Similar to the effects of miR-200b upregulation, knockdown of ZEB1 led to a significant decrease in the proliferation (Figure 6C), migration (Figure 7A), and invasion (Figure 7B) in MG63 and U2OS cells when compared to the 


\section{A}

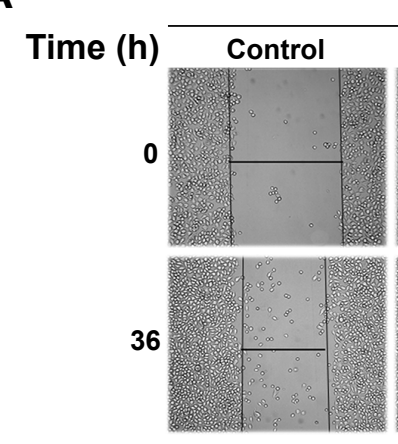

U2OS
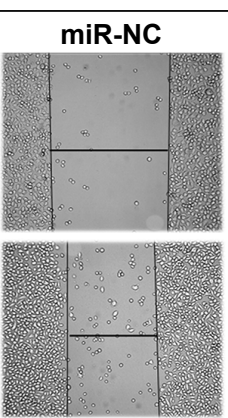
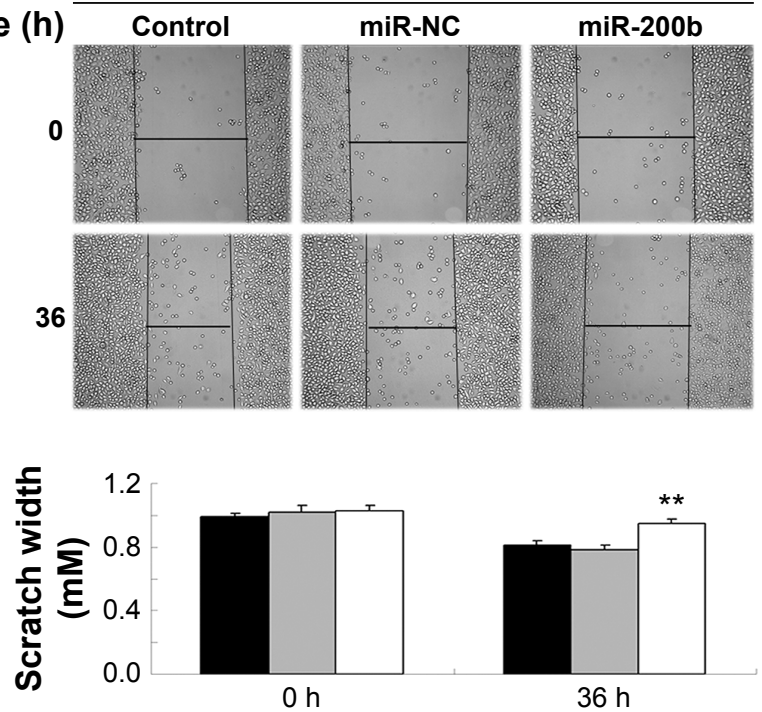

Control $\square$ miR-NC $\square$ miR-200b

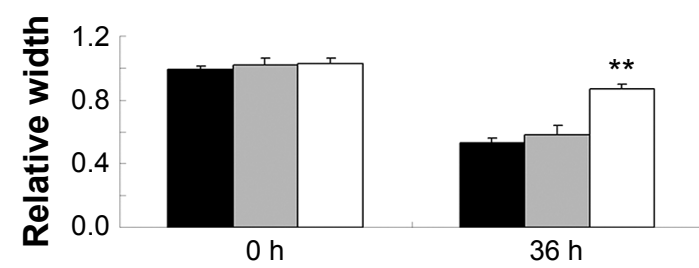

B

U2OS
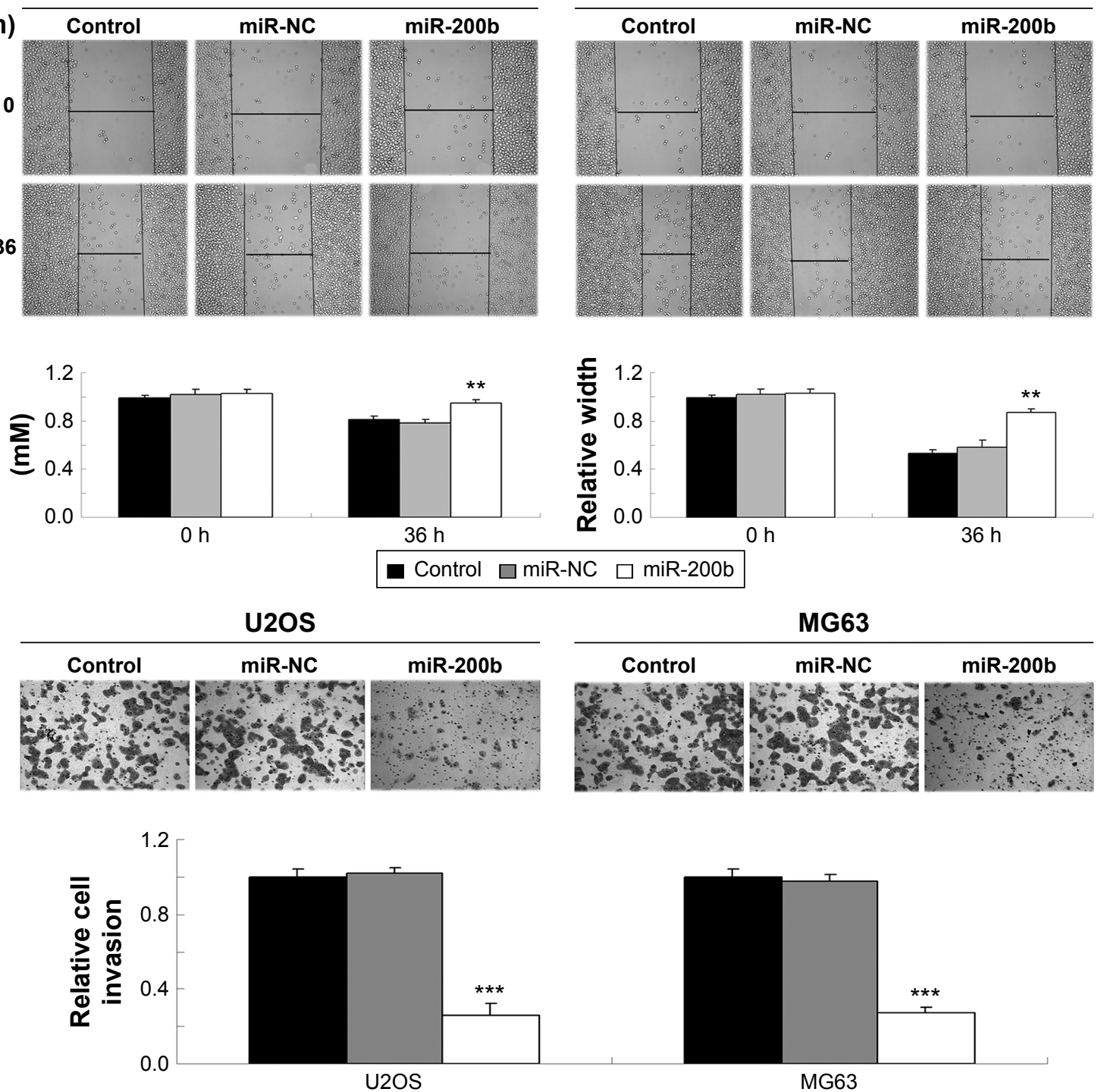

\section{MG63}

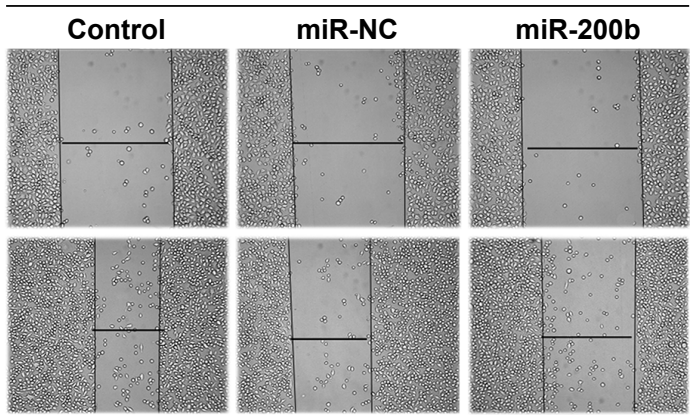

Control $\square$ miR-NC $\square$ miR-200b

Figure 3 miR-200b inhibits invasive ability of U2OS and MG63 cells.

Notes: Wound healing assay (A) and transwell assay (B) were performed to determine cell migration and invasion in osteosarcoma U2OS and MG63 cells transfected with miR-200b mimic or scramble miR (miR-NC). Nontransfected U2OS and MG63 cells were used as control. $* * P<0.01$, $* * * P<0.001$ versus miR-NC. The error bars indicate standard deviation. Magnification is $40 \times$.

Abbreviations: miR, microRNA; NC, negative control; h, hours.

control group, respectively. Accordingly, we suggest that downregulation of ZEB1 caused by miR-200b upregulation may suppress osteosarcoma growth and metastasis.

\section{Expression of ZEBI is significantly increased and reversely correlated to miR-200b levels in osteosarcoma tissues}

Finally, we detected the protein levels of ZEB1 in osteosarcoma tissues and their matched adjacent nontumor tissues. Our data showed that the protein expression of ZEB1 was significantly increased in osteosarcoma tissues compared to their matched adjacent nontumor tissues (Figure 8A). Moreover, we showed a reverse correlation between the miR-200b expression and ZEB1 expression in osteosarcoma tissues (Figure 8B). These data further suggest that the upregulation of ZEB1 in osteosarcoma may partly be at least due to the downregulation of miR-200b.

\section{Discussion}

Some miRs have been demonstrated to be deregulated and act as a tumor suppressor or oncogene in osteosarcoma. Han et al reported that miR-124 was significantly downregulated in 
A

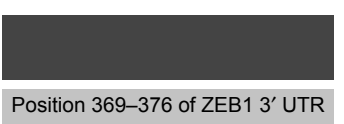

hsa-miR-200b
Predicted consequential pairing of target

region (top) and miRNA (bottom)

$5^{\prime}$... A AUUguUUUAUCUUAUCAGUAUUA $\ldots$

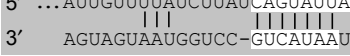

C

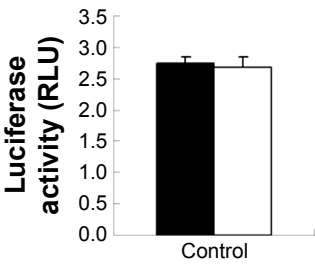

U2OS

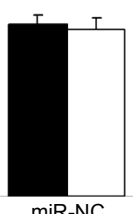

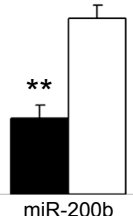

B WT 3'-UTR of ZEB1 5 ' -... UUUAUCAGUAUUA ... - - $3^{\prime}$

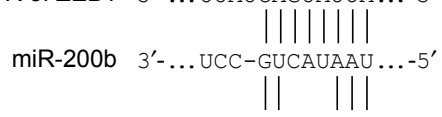

MT 3'-UTR of ZEB1 $55^{\prime}-\ldots$ UUAUCACAUUUA ... - -3'

D

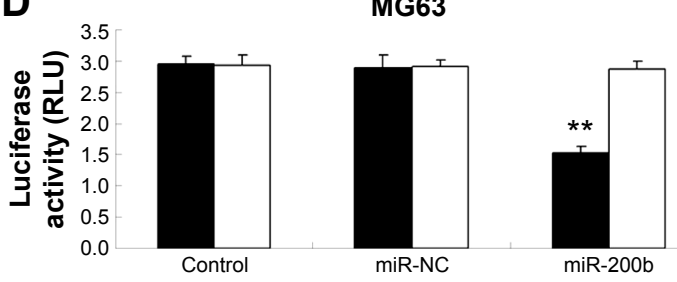

Figure 4 miR-200b directly targets to ZEBI.

Notes: (A) TargetScan software predicated that ZEBI was a direct target gene of miR-200b. (B) The seed sequences of miR-200b in the WT and MT 3'-UTR of ZEBI are indicated. The luciferase activity was notably decreased in osteosarcoma U2OS (C) and MG63 (D) cells cotransfected with miR-200b mimics and pMIR-ZEBI but unaltered in U2OS and MG63 cells cotransfected with miR-200b mimics and PMIR-Mut ZEBI. Control: cells only transfected with PMIR-ZEBI or PMIR-Mut ZEBI, respectively. NC: cells cotransfected with scramble miR and $p$ MIR-ZEBI or PMIR-Mut ZEBI, respectively. $* * P<0.0$ I versus NC. The error bars indicate standard deviation.

Abbreviations: miR, microRNA; WT, wild type; MT, mutant type; UTR, untranslated region; NC, negative control.

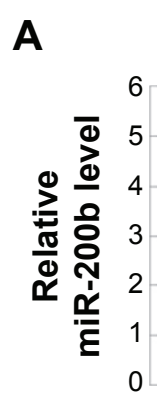

B

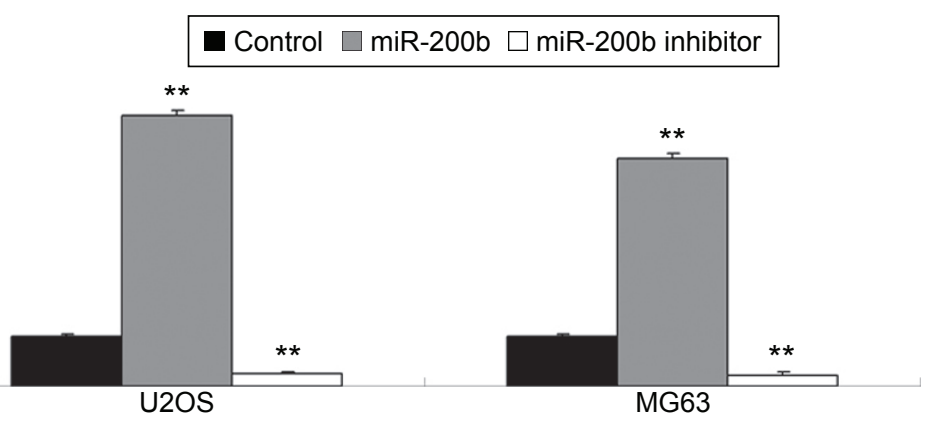

miR-200b
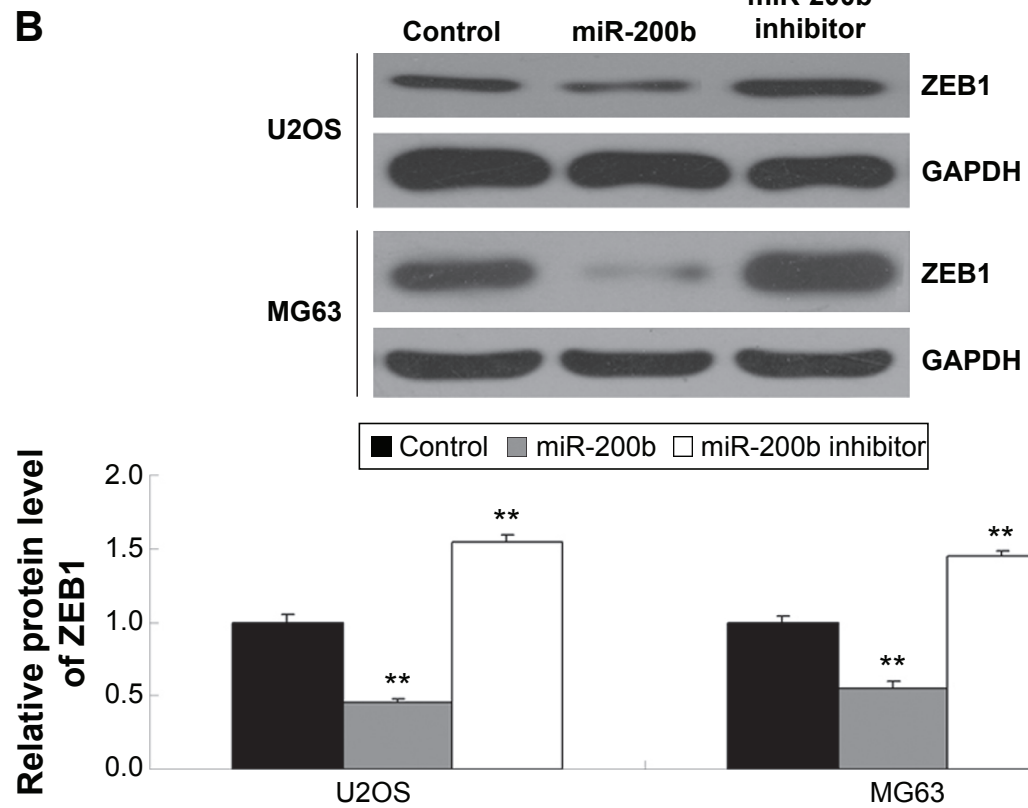

Control $\square$ miR-200b $\square$ miR-200b inhibitor

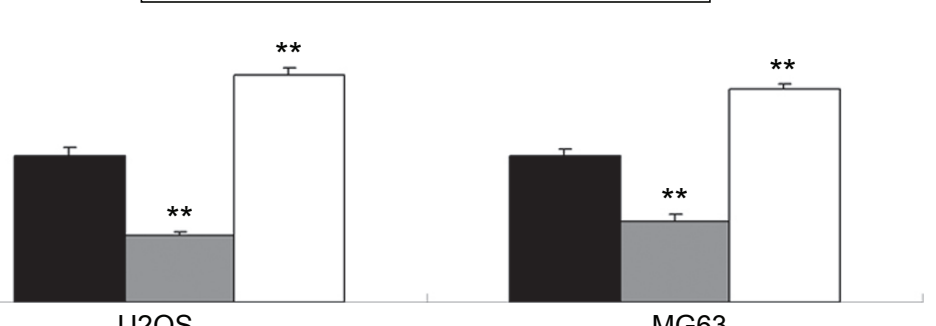

U2OS
MG63

Figure 5 miR-200b regulates ZEBI protein expression.

Notes: (A) Real-time RT-PCR was conducted to determine the relative miR-200b level in osteosarcoma U2OS and MG63 cells transfected with miR-200b mimic or inhibitor. (B) Western blot was conducted to examine the protein expression of ZEBI in each group. GAPDH was used as internal reference gene. U2OS and MG63 transfected with scramble miR cells were used as control. $* * P<0.01$. The error bars indicate standard deviation. Magnification is $40 \times$.

Abbreviations: miR, microRNA; RT-PCR, reverse transcription-polymerase chain reaction. 


\section{A}
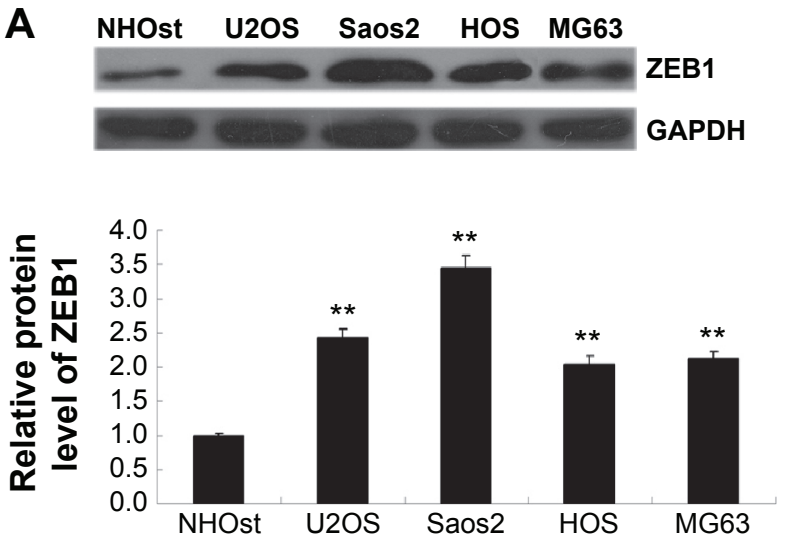

C

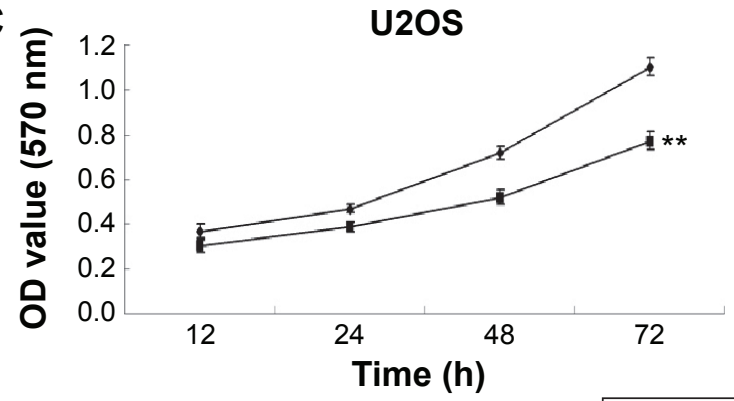

B
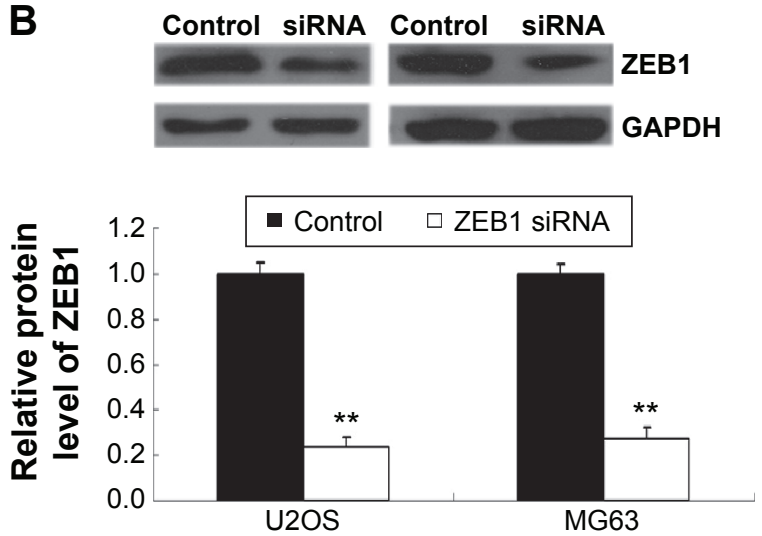

MG63

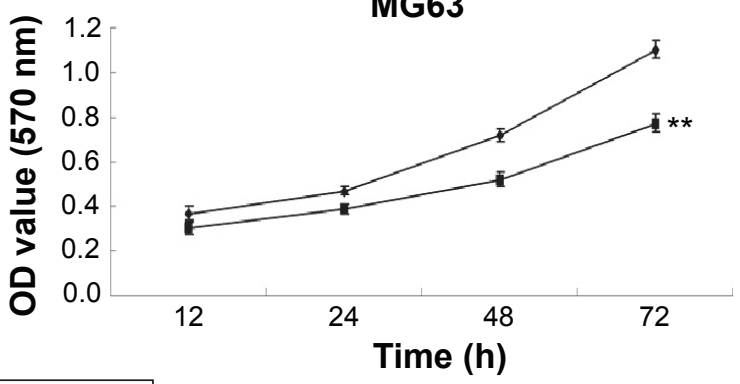

Figure 6 Knockdown of ZEBI inhibits osteosarcoma cell proliferation.

Notes: (A) Western blot was conducted to examine the protein expression of ZEBI in osteosarcoma U2OS, Saos2, HOS, and MG63 and normal osteoblast cell line NHOst. (B) Western blot was conducted to examine the protein expression of ZEBI in U2OS and MG63 cells transfected with ZEBI siRNA. (C) MTT assay was performed to determine the cell proliferation of U2OS (left) and MG63 (right) cells in each group. U2OS and MG63 cells transfected with scramble were used as control. $* * P<0.01$ versus control. The error bars indicate standard deviation. Magnification is 40x.

Abbreviations: siRNA, small interfering RNA; h, hours; OD, optical density.

osteosarcoma, and low expression of miR-124 was associated with advanced clinical stage, positive distant metastasis, poor response to neoadjuvant chemotherapy, and poor prognosis. ${ }^{19}$ MiR-194 was found to suppress osteosarcoma cell proliferation and metastasis by targeting $\mathrm{CDH} 2$ and IGF1R. ${ }^{20}$ Recently, Li et al reported that miR-200b was lost in osteosarcoma. ${ }^{14}$ However, the exact role of miR-200b in osteosarcoma and the underlying mechanism remains still to be fully uncovered. In this study, we found that miR-200b was frequently downregulated in osteosarcoma tissues and cell lines. Moreover, reduced miR-200b expression was correlated with the advanced clinical stage and positive metastasis of osteosarcoma, suggesting that deregulation of miR-200b is involved in the malignant progression of osteosarcoma.

We further showed that enforced expression of miR-200b led to a significant decrease in the proliferation, migration, and invasion of osteosarcoma cells, suggesting that miR$200 \mathrm{~b}$ acts as a tumor suppressor in osteosarcoma. In fact, the suppressive role of miR-200b has also been demonstrated in some other cancer types. ${ }^{21,22}$ For instance, miR-200b inhibits cell proliferation, migration, and enhanced chemosensitivity by inhibition of Bmi-1 in prostate cancer. ${ }^{8}$ Kurashige et al demonstrated that miR-200b suppressed cell proliferation, invasion, and migration of gastric carcinoma cells by directly targeting ZEB2. ${ }^{21}$ Besides, miR-200b suppresses cell growth, migration, and invasion of nasopharyngeal carcinoma cells by targeting Notch $1 .{ }^{23}$ However, several studies also reported that miR-200b played an oncogenic role in several cancer types. Fu et al showed that miR$200 \mathrm{~b}$ stimulates the growth of TGFBR2-null colorectal cancer by inhibition of p27/kip $1 .{ }^{24}$ Besides, miR-200b was also found to target the tumor suppressor PTEN and thus act as an oncogene in endometrioid endometrial carcinoma. ${ }^{25}$ Therefore, the exact role of miR-200b seems to be tumor-specific.

As the function of miRs is through negatively mediating the expression of their target genes,${ }^{26}$ we further focused on the putative targets of miR-200b and found that miR-200b directly targeted ZEB1 and negatively mediated its protein expression in osteosarcoma cells.

ZEB1 is a member of the deltaEF1 family of twohanded zinc-finger factors and acts as a transcriptional 


\section{A}

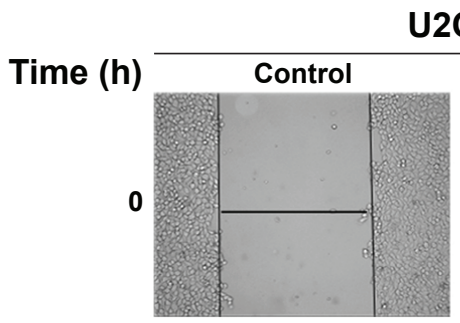

U2OS
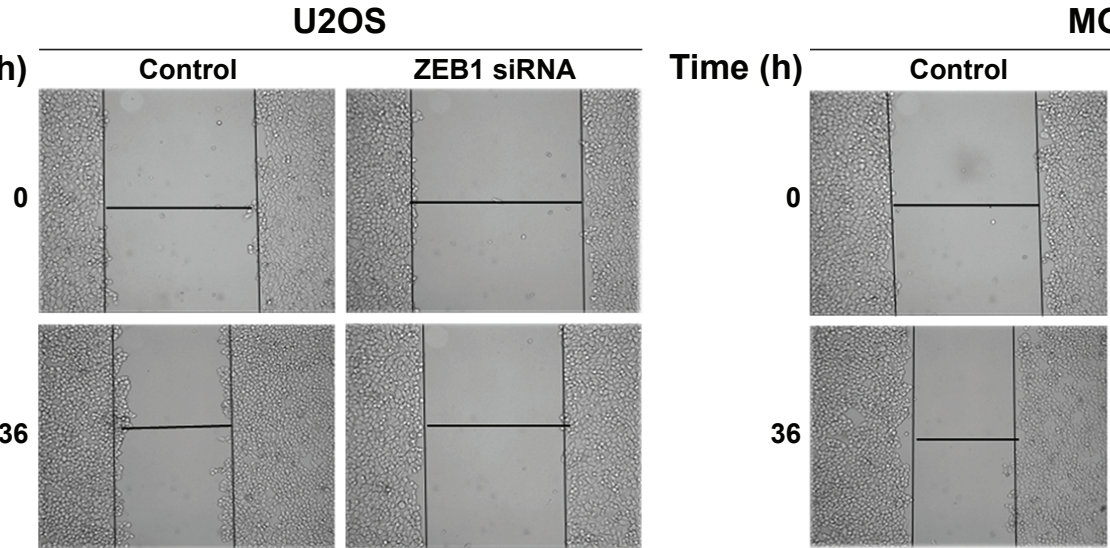

MG63
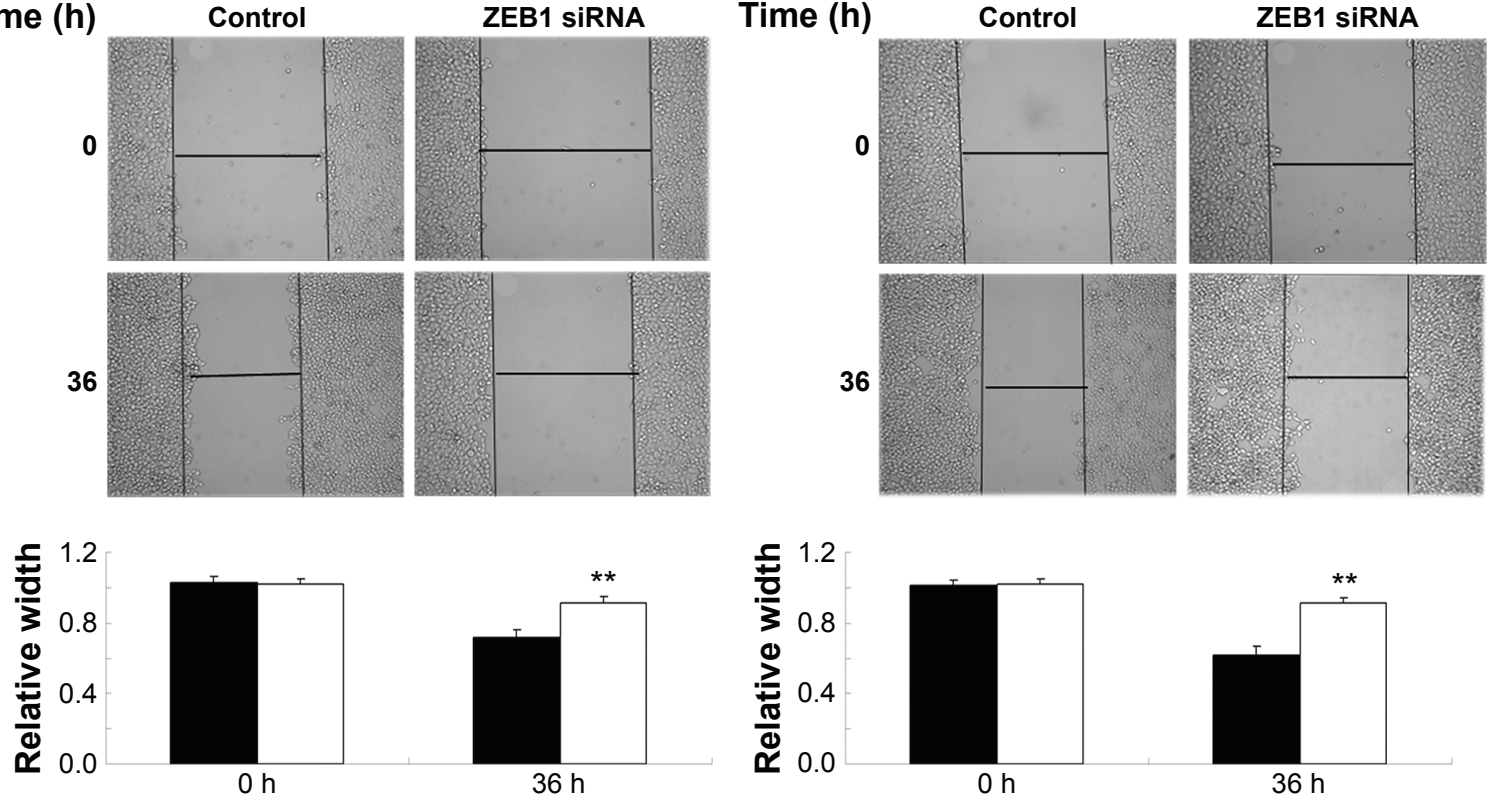

$\square$ Control $\square$ ZEB1 siRNA

B
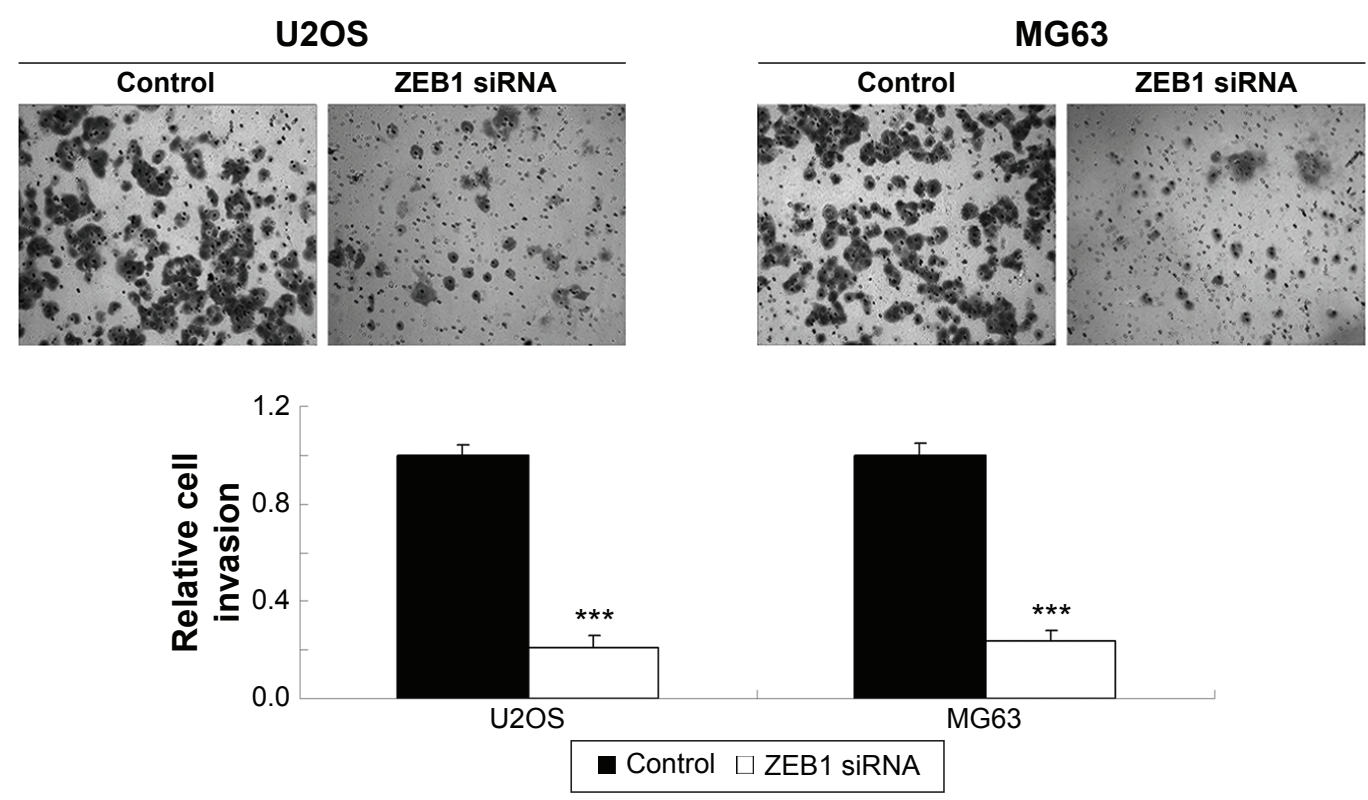

Figure 7 Knockdown of ZEBI inhibits osteosarcoma cell invasion.

Notes: Wound healing assay $(\mathbf{A})$ and transwell assay $(\mathbf{B})$ were performed to determine cell migration and invasion of U2OS and MG63 cells transfected with ZEBI siRNA U2OS and MG63 cells transfected with scramble were used as control. $* * P<0.0$ l, $* * * P<0.001$ versus control. Magnification is $40 \times$.

Abbreviations: siRNA, small interfering RNA; h, hours.

factor. ${ }^{27}$ It has been well established that ZEB1 is involved in the malignant progression of multiple types of human cancers. ${ }^{27,28}$ For instance, overexpression of ZEB1 promotes tumor invasiveness and confers unfavorable prognosis in esophageal squamous cell carcinoma. ${ }^{29}$ Besides, upregulated expression of ZEB1 in cancer cells and in stromal cancerassociated fibroblasts was associated with poor prognosis of patients with pancreatic ductal adenocarcinoma.$^{28}$ Moreover,
ZEB1 is an epithelial-to-mesenchymal inducer and plays a promoting role in cancer metastasis..$^{30}$ Recently, ZEB1 was found to be significantly higher in the osteosarcoma tissues when compared with that in normal bone tissue, and the increased ZEB1 level was associated with positive lung metastasis. ${ }^{31}$ In this study, we found that ZEB1 was significantly upregulated in osteosarcoma cells compared to normal osteoblast cell line NHOst, and knockdown of 

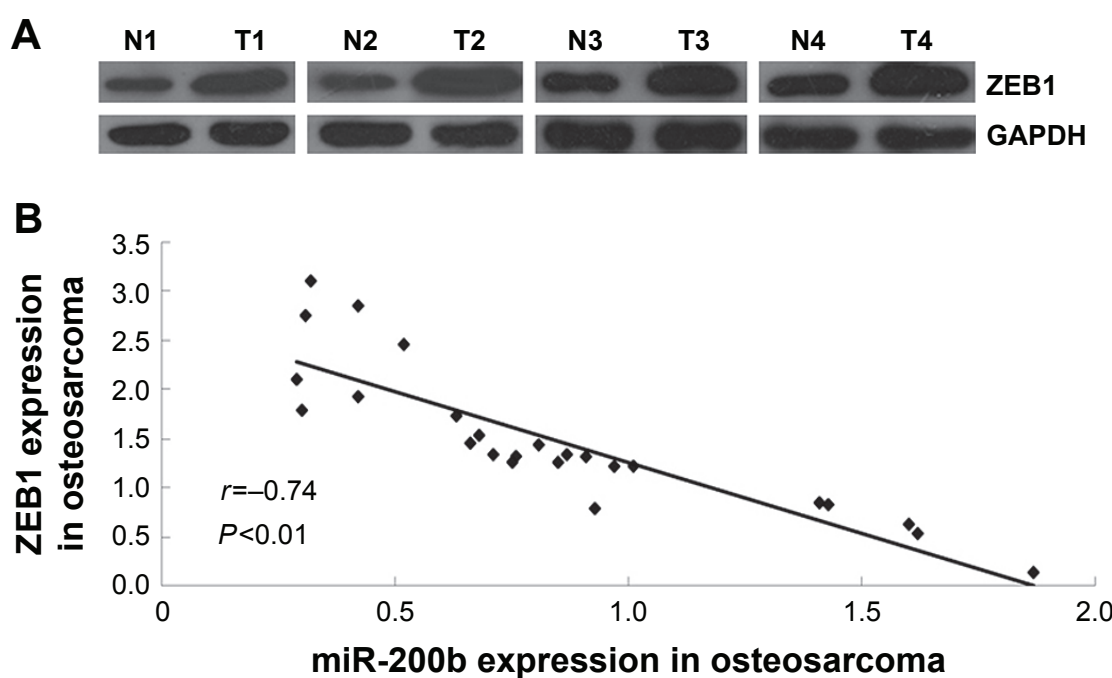

Figure 8 miR-200b is negatively correlated with ZEBI.

Notes: (A) Western blotting assay was conducted to determine the protein expression of ZEBI in osteosarcoma tissues compared to their matched adjacent normal tissues. (B) A reverse correlation between the miR-200b expression and ZEBI expression is indicated in 25 patients. The error bars indicate standard deviation. Magnification is $40 \times$. Abbreviation: miR, microRNA.

ZEB1 suppressed the proliferation, migration, and invasion of osteosarcoma cells, suggesting that ZEB1 may be involved in miR-200b-mediated malignant phenotypes of osteosarcoma cells. Shen et al also found that knockdown of ZEB1 led to a significant decrease in osteosarcoma cell migration. ${ }^{31}$ In addition, ZEB1 was also mediated by other miRs in osteosarcoma. For instance, miR-141 and miR-429 were found to inhibit cell proliferation while inducing cell apoptosis via targeting ZEB1 in osteosarcoma cells. ${ }^{32,33}$ Furthermore, ZEB1 is also targeted by another member of miR-200 family, miR-200c, in gastric cancer, breast cancer, and head and neck squamous cell carcinoma. ${ }^{34-36}$ Elevated expression of ZEB1, an EMT inducer, enables tumor cells to detach from the primary tumor and invade into the surrounding tissue. ${ }^{37}$ And miR-200 family, including miR-200b and miR-200c, is the antagonist of ZEB1 in controlling EMT, and there is a double-negative feedback loop between miR-200 family and ZEB1. ${ }^{38-40}$ Thus, it seems conceivable that there is an interaction of miR-200 family that regulates EMT by targeting ZEB1.

Finally, we showed that ZEB1 was frequently upregulated in osteosarcoma tissues compared to their adjacent normal tissues, and its expression was reversely correlated to the miR$200 \mathrm{~b}$ levels in osteosarcoma tissues. These findings further suggest that the upregulation of ZEB1 in osteosarcoma may partly be at least due to the downregulation of miR-200b.

\section{Conclusion}

In conclusion, this study demonstrated that miR-200b was frequently downregulated in osteosarcoma and the reduced expression of miR-200b was associated with the malignant progression of osteosarcoma. In vitro study revealed that
miR-200b plays a suppressive role in mediating the proliferation, migration, and invasion of osteosarcoma cells probably via directly inhibiting the protein expression of its target gene ZEB1. Therefore, miR-200b/ZEB1 may be a potential therapeutic target for osteosarcoma.

\section{Acknowledgments}

This work was supported by the National Natural Science Foundation of China (81402224), the Provincial Science Foundation of Hunan (2015JJ3139), the Scientific Research Project of the Development and Reform Commission of Hunan Province ([2014]658-8), the Scientific Research Project of Science and Technology Bureau of Hunan Province (2012FJ6001), the Scientific Research Project of Science and Technology Office of Changsha City (K1203040-31), the Scientific Research Project of Health and Family Planning Commission of Hunan Province (B2014-12), and the College Student's Innovation and Entrepreneurship Project of Central South University (DL14505).

\section{Disclosure}

The authors report no conflicts of interest in this work.

\section{References}

1. Thompson LD. Osteosarcoma. Ear Nose Throat J. 2013;92(7): 288-290.

2. Liang W, Gao B, Fu P, et al. The miRNAs in the pathogenesis of osteosarcoma. Front Biosci. 2013;18:788-794.

3. Namlos HM, Meza-Zepeda LA, Baroy T, et al. Modulation of the osteosarcoma expression phenotype by microRNAs. PLoS One. 2012; 7(10):e48086.

4. Esquela-Kerscher A, Slack FJ. Oncomirs - microRNAs with a role in cancer. Nat Rev Cancer. 2006;6(4):259-269.

5. Choi E, Choi E, Hwang KC. MicroRNAs as novel regulators of stem cell fate. World J Stem Cells. 2013;5(4):172-187. 
6. Yao Y, Hu J, Shen Z, et al. MiR-200b expression in breast cancer: a prognostic marker and act on cell proliferation and apoptosis by targeting Sp1. J Cell Mol Med. 2015;19(4):760-769.

7. Williams LV, Veliceasa D, Vinokour E, Volpert OV. miR-200b inhibits prostate cancer EMT, growth and metastasis. PLoS One. 2013; 8(12):e83991.

8. Yu J, Lu Y, Cui D, et al. miR-200b suppresses cell proliferation, migration and enhances chemosensitivity in prostate cancer by regulating Bmi-1. Oncol Rep. 2014;31(2):910-918.

9. Peng F, Jiang J, Yu Y, et al. Direct targeting of SUZ12/ROCK2 by miR$200 \mathrm{~b} / \mathrm{c}$ inhibits cholangiocarcinoma tumourigenesis and metastasis. Br J Cancer. 2013;109(12):3092-3104.

10. Tang H, Deng M, Tang Y, et al. miR-200b and miR-200c as prognostic factors and mediators of gastric cancer cell progression. Clin Cancer Res. 2013;19(20):5602-5612.

11. Kohler CU, Bryk O, Meier S, et al. Analyses in human urothelial cells identify methylation of miR-152, miR-200b and miR-10a genes as candidate bladder cancer biomarkers. Biochem Biophys Res Commun 2013;438(1):48-53.

12. Ding W, Dang H, You H, et al. miR-200b restoration and DNA methyltransferase inhibitor block lung metastasis of mesenchymal-phenotype hepatocellular carcinoma. Oncogenesis. 2012;1:e15.

13. Sun L, Yao Y, Liu B, et al. MiR-200b and miR-15b regulate chemotherapyinduced epithelial-mesenchymal transition in human tongue cancer cells by targeting BMI1. Oncogene. 2012;31(4):432-445.

14. Li Y, Zhang J, Zhang L, Si M, Yin H, Li J. Diallyl trisulfide inhibits proliferation, invasion and angiogenesis of osteosarcoma cells by switching on suppressor microRNAs and inactivating of Notch-1 signaling. Carcinogenesis. 2013;34(7):1601-1610.

15. Liu Z, Long X, Chao C, et al. Knocking down CDK4 mediates the elevation of let-7c suppressing cell growth in nasopharyngeal carcinoma. BMC Cancer. 2014;14:274.

16. Krek A, Grün D, Poy MN, et al. Combinatorial microRNA target predictions. Nature Genetics. 2005;37:495-500.

17. Garwal V, Bell GW, Nam J, Bartel DP. Predicting effective microRNA target sites in mammalian mRNAs. eLife. 2015;4:e05005.

18. John B, Enright AJ, Aravin A, Tuschl T, Sander C, Marks DS. Human MicroRNA targets. PLoS Biol. 2005;3(7):e264.

19. Han G, Wang Y, Bi W, Jia J, Wang W. MicroRNA-124 functions as a tumor suppressor and indicates prognosis in human osteosarcoma Exp Ther Med. 2015;9(3):679-684.

20. Han K, Zhao T, Chen X, et al. microRNA-194 suppresses osteosarcoma cell proliferation and metastasis in vitro and in vivo by targeting $\mathrm{CDH} 2$ and IGF1R. Int J Oncol. 2014;45(4):1437-1449.

21. Kurashige J, Kamohara H, Watanabe M, et al. MicroRNA-200b regulates cell proliferation, invasion, and migration by directly targeting ZEB2 in gastric carcinoma. Ann Surg Oncol. 2012;19(suppl 3):S656-S664.

22. Feng B, Wang R, Song HZ, Chen LB. MicroRNA-200b reverses chemoresistance of docetaxel-resistant human lung adenocarcinoma cells by targeting E2F3. Cancer. 2012;118(13):3365-3376.

23. Yang X, Ni W, Lei K. miR-200b suppresses cell growth, migration and invasion by targeting Notch1 in nasopharyngeal carcinoma. Cell Physiol Biochem. 2013;32(5):1288-1298.

24. Fu Y, Liu X, Zhou N, et al. MicroRNA-200b stimulates tumour growth in TGFBR2-null colorectal cancers by negatively regulating p27/kip1. J Cell Physiol. 2014;229(6):772-782.

OncoTargets and Therapy

\section{Publish your work in this journal}

OncoTargets and Therapy is an international, peer-reviewed, open access journal focusing on the pathological basis of all cancers, potential targets for therapy and treatment protocols employed to improve the management of cancer patients. The journal also focuses on the impact of management programs and new therapeutic agents and protocols on
25. Yoneyama K, Ishibashi O, Kawase R, Kurose K, Takeshita T. miR-200a, miR-200b and miR-429 are onco-miRs that target the PTEN gene in endometrioid endometrial carcinoma. Anticancer Res. 2015;35(3): $1401-1410$.

26. Huang JT, Wang J, Srivastava V, Sen S, Liu SM. MicroRNA machinery genes as novel biomarkers for cancer. Front Oncol. 2014;4:113.

27. Guan H, Liang W, Xie Z, et al. Down-regulation of miR-144 promotes thyroid cancer cell invasion by targeting ZEB1 and ZEB2. Endocrine. 2015;48(2):566-574.

28. Bronsert P, Kohler I, Timme S, et al. Prognostic significance of Zinc finger E-box binding homeobox 1 (ZEB1) expression in cancer cells and cancer-associated fibroblasts in pancreatic head cancer. Surgery. 2014; 156(1):97-108.

29. Yang X, Wang Q, Dai W, Zhang J, Chen X. Overexpression of zinc finger E-box binding homeobox factor 1 promotes tumor invasiveness and confers unfavorable prognosis in esophageal squamous cell carcinoma. Tumour Biol. 2014;35(12):11977-11984.

30. Al-KhalafHH, Aboussekhra A. MicroRNA-141 and microRNA-146b-5p inhibit the prometastatic mesenchymal characteristics through the RNAbinding protein AUF1 targeting the transcription factor ZEB1 and the protein kinase AKT. J Biol Chem. 2014;289(45):31433-31447.

31. Shen A, Zhang Y, Yang H, Xu R, Huang G. Overexpression of ZEB1 relates to metastasis and invasion in osteosarcoma.J Surg Oncol. 2012; 105(8):830-834.

32. Xu H, Mei Q, Xiong C, Zhao J. Tumor-suppressing effects of miR-141 in human osteosarcoma. Cell Biochem Biophys. 2014;69(2):319-325.

33. Liu X, Liu Y, Wu S, et al. Tumor-suppressing effects of miR-429 on human osteosarcoma. Cell Biochem Biophys. 2014;70(1):215-224.

34. Zhou X, Wang Y, Shan B, et al. The downregulation of miR-200c/141 promotes ZEB1/2 expression and gastric cancer progression. Med Oncol. 2015;32(1):428.

35. Bai WD, Ye XM, Zhang MY, et al. MiR-200c suppresses TGF-beta signaling and counteracts trastuzumab resistance and metastasis by targeting ZNF217 and ZEB1 in breast cancer. Int $J$ Cancer. 2014;135(6):1356-1368.

36. Tamagawa S, Beder LB, Hotomi M, et al. Role of miR-200c/miR141 in the regulation of epithelial-mesenchymal transition and migration in head and neck squamous cell carcinoma. Int $J$ Mol Med. 2014;33(4):879-886.

37. Magenta A, Cencioni C, Fasanaro P, et al. miR-200c is upregulated by oxidative stress and induces endothelial cell apoptosis and senescence via ZEB1 inhibition. Cell Death Differ. 2011;18(10):1628-1639.

38. Sundararajan V, Gengenbacher N, Stemmler MP, Kleemann JA, Brabletz T, Brabletz S. The ZEB1/miR-200c feedback loop regulates invasion via actin interacting proteins MYLK and TKS5. Oncotarget. 2015; 6(29):27083-27096.

39. Burk U, Schubert J, Wellner U, et al. A reciprocal repression between ZEB1 and members of the miR-200 family promotes EMT and invasion in cancer cells. EMBO Rep. 2008;9(6):582-589.

40. Gregory PA, Bert AG, Paterson EL, et al. The miR-200 family and miR-205 regulate epithelial to mesenchymal transition by targeting ZEB1 and SIP1. Nat Cell Biol. 2008;10(5):593-601.

patient perspectives such as quality of life, adherence and satisfaction The manuscript management system is completely online and includes a very quick and fair peer-review system, which is all easy to use. Visit http://www.dovepress.com/testimonials.php to read real quotes from published authors.

\section{Dovepress}

